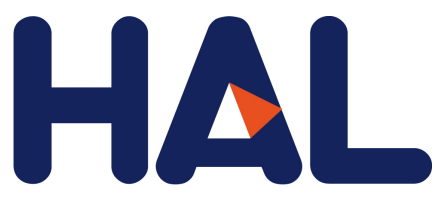

archives-ouvertes

\title{
From legal to normative: A combined social representations and sociocognitive approach to diagnosing cultural change triggered by new environmental laws
}

Raquel Bertoldo, Paula Castro

\section{To cite this version:}

Raquel Bertoldo, Paula Castro. From legal to normative: A combined social representations and sociocognitive approach to diagnosing cultural change triggered by new environmental laws. Culture and Psychology, SAGE Publications, 2018, 10.1177/1354067X18790730 . hal-01888409

\section{HAL Id: hal-01888409 \\ https://hal.archives-ouvertes.fr/hal-01888409}

Submitted on 5 Oct 2018

HAL is a multi-disciplinary open access archive for the deposit and dissemination of scientific research documents, whether they are published or not. The documents may come from teaching and research institutions in France or abroad, or from public or private research centers.
L'archive ouverte pluridisciplinaire HAL, est destinée au dépôt et à la diffusion de documents scientifiques de niveau recherche, publiés ou non, émanant des établissements d'enseignement et de recherche français ou étrangers, des laboratoires publics ou privés. 
From legal to normative: A combined social representations and sociocognitive approach to diagnosing cultural change triggered by new environmental laws

\author{
Raquel Bertoldo
}

Aix Marseille Univ, Univ Nice Sophia Antipolis, Avignon Université, CNRS, ESPACE, Nice, France

Instituto Universitário de Lisboa (ISCTE-IUL) \& CIS-IUL

\author{
Paula Castro
}

Instituto Universitário de Lisboa (ISCTE-IUL) \& CIS-IUL 


\begin{abstract}
Inconsistency between the expressed support for resource-conservation ideas and behaviours has emphasised the need to develop a better understanding of the psychosocial processes through which formal laws (reified universe) also become informal norms (consensual universe). Experimental paradigms of the sociocognitive approach to social norms are able to assess if cultural change fostered by the legal/reified universe have been incorporated by society to the level of influencing, and being expected, in interpersonal communications. This article proposes to combine elements from the social representations theory and the sociocognitive approach to social norms in a diagnose proposal for cultural change (appropriation and consensualisation dimensions). Through a self-presentation paradigm, results of Study 1 show that conservation beliefs and behaviours are indeed used in interpersonal contexts in order to be well-seen; yet this informal valorisation is context-dependant. In Study 2 a hetero-evaluation paradigm was used. Results show that conservation beliefs are socially valued and crucial for people to be positively seen (appropriation). Yet the expression of conservation behaviours is not required (consensualisation). Overall, these results show that conservation beliefs and behaviours have become informal norms in Portugal. Still, this valorisation is not yet homogeneous; it partially tolerates belief-behaviour inconsistency, a typical dynamic of emancipated representations.
\end{abstract}

Keywords: social representations, sociocognitive approach, social norms, sustainabilty, legal innovation. 
In the last decades ecological and climate change-related problems have been increasingly tackled through a type of governance in which new legal and policy tools are first developed at the global or supra-national level, and are then passed on to the national and local levels (Giddens, 2009). The European Union (EU), in particular, has put numerous environmental Directives into place to be transposed to member-states' national environmental legal frameworks (Castro, 2012; Batel, Devine-Wright \& Tangeland, 2013): analysts have remarked that for joining the EU, applicant countries are today required to adopt more than 450 pieces of environmental legislation (Börzel \& Fagan, 2015). This means that EU public spheres are called to adjust to a high number of new environmental laws and regulations, several of which promote a variety of resource-conservation actions for ecological purposes (e.g., recycling, or energy efficiency; Castro, 2012; Batel et al., 2013). The literature indicates that the goals of this governance, advanced through several governmental initiatives (e.g., selective disposal bins, media campaigns), receive clear support from EU publics (Gaskell et al., 2011). However, it also indicates that despite support, behaviours are changing rather slowly, remaining persistently inconsistent with beliefs (Lavergne \& Pelletier, 2015).

These two facts - EU's strong reliance on legal means for tackling environmental problems, and the enduring inconsistency between beliefs and behaviours - both suggest that social and cultural psychology need to offer more attention to the psychosocial processes through which new laws and policies contribute (or fail to contribute) to social and cultural change (Castro \& Batel, 2008; Jensen \& Wagoner, 2009). In the terms of the approach of social representations, this means: (1) studying the processes through which formal laws crafted in legal/reified universes (Moscovici, 1988) are able to enter consensual universes, thus becoming also informal norms; (2) developing criteria for recognizing in communication and Self-Other relations to what extent this 
transference has occurred (Castro, 2012), and cultural change is being sustained in consensual universes.

These questions have been studied simultaneously by the theory of social representations (TSR) and the sociocognitive approach to social norms (Dubois, 2003). These two fields developed in parallel as independent approaches. The social representations approach focusses on how social knowledge supports both social change and social stability and re-production (Moscovici, 2000; Marková et al., 2007; Castro \& Batel, 2008). The sociocognitive approach to social norms on the other hand is interested in understanding how social norms, while implicit, greatly contribute to the re-production of social structures and representations (Dubois, 2003).

With the aim of proposing an integrated theoretical frame for the abovementioned goals, this article proposes to combine elements from the theory of social representations (Moscovici, 2000) and of the sociocognitive approach (Dubois, 2003). Both approaches view social and cultural change not as the sum of individual perspectives, but as involving all levels of a society, for which the transformation of shared belief systems - generated, maintained and transformed in Self-Other relations is pivotal (Doise, 1980; Dubois, 2003; Castro, 2012; Marková et al., 2007). We argue that integrating these approaches can extend our understanding of the processes involved in the 'social change cycle' (Jensen \& Wagoner, 2009) in which institutional, and initially transcendent, rules from a reified universe (new laws) become immanent in various types of social contexts and practices, entering namely the communicative practices of self-presentation and hetero-judgement.

Despite sharing many assumptions on the inter-dependence of social and individual worlds, the two approaches have rarely been combined for analysing cultural change driven by new laws (but see Bertoldo, 2014). For this reason, we will start by 
explaining how, when combined, they call for an integrated analysis of the appropriation dimension - how norms become immanent in individuals' behaviours and of the consensualisation dimension - how social groups might differ in how widely they value the new norms.

After building this integrated theoretical frame, we will illustrate its potentialities for diagnosing cultural change through two studies. The studies explore the extent to which ideas and behaviours encouraged by new resource-conservation laws transposed from EU Directives (promoting recycling and energy saving) have become informally valued in Portugal. This is done by resorting to paradigms developed by the sociocognitive approach to identify the use of these ideas and behaviours in interpersonal contexts: the self-presentation and hetero-evaluation paradigms. These paradigms appeal directly to the cultural competence of participants as "citizens of socio-cultural worlds" (Jovchelovitch, 2011, p. 12.4) and are here used as standardized appraisals of the extent to which informal communicative practices reflect cultural change. The communicative practices examined - self-presentation and heteroevaluation - are thus here viewed as social and interpersonal processes through which new meaning categories filter into and are valued in different social contexts, or 'audiences' (Goffman, 1959).

\section{The appropriation dimension: from transcendent laws to immanent norms}

The Theory of Social Representations (TSR) proposes that when laws destined to bring about social and cultural change enter into force in a nation, for many people they are still transcendent to actions (Harré, 1998; Castro \& Batel, 2008), i.e. they remain a “written instruction" (Harré, 2002, p. 116) decontextualized from the individuals' immediate environment (Boulanger \& Christensen, in press). Then a period follows 
when they enter public sphere discussions, and are debated and elaborated in Self-Other relations through inter-personal and mediated communication, as well as inner dialogue (Castro, 2012; Mouro \& Castro, 2016; Marková, 2006; Marková et al., 2007). Through these debates and dialogues (Marková, 2006) the new ideas may become progressively invested with meaning, becoming part of a 'transpersonal dimension' and leading to a certain type of actions being expected within given contexts (Grossen \& Orvig, 2011). This may eventually make the laws become immanent representations, deducible from concrete actions (Castro \& Batel, 2008; Harré, 1998; Jensen \& Wagoner, 2009).

The appropriation (Rogoff, 1995) process through which new norms progressively become implicit in behaviour is a culturally enabled psychological process (Valsiner \& Lawrence, 1997). Meanings shared through social interactions are progressively reconstructed at the interpersonal and psychological levels (Valsiner \& Lawrence, 1997; Zittoun \& Gillespie, 2015). As a culturally enabled psychological process (Valsiner \& Lawrence, 1997), the appropriation of new ideas - e.g. those proposed by new laws - is a continuous process involving the individual and the social levels (Moscovici, 1988). In this sense, individuals move in the world under the guidance of socially shared interpretations.

For example, many of our current public and private hygiene standards evolved from formal laws (Foucault, 1982). Representations about hygiene standards that in the 19th century were still transcendent to the actions of many are today immanent and implicit in the actions of almost everybody (Castro, 2012): and it is not a frequent - or valued - conversational practice to express disregard for them. Thus, ideas and behaviours initially proposed by an external Institutional-Other (Mouro \& Castro, 2016) as (transcendent) rules can in time be appropriated by public spheres, and therefore implicitly expected in inter-individual encounters. From formal suggestions, they 
became therefore informally valued in a growing variety of private and public contexts (Elcheroth et al., 2011; Grossen \& Orvig, 2011). Regarding new laws, as the social value of the ideas they incorporate increases, they progressively work as "semiotic constraints" contributing for a common social organisation (Valsiner, 2003). However, diagnostic criteria for identifying the extent to which these processes of cultural change and constraint are advanced, making certain ideas valued in a growing variety of contexts, are still lacking and are today much needed (Castro, 2012; Castro \& Batel, 2008).

Here lies the interest of the methods proposed by the sociocognitive approach. This perspective assumes that some of the ideas that are central to our social functioning are so widely valued, shared and implicit, that they are opaque to our everyday perception (Dubois, 2003). From this perspective, new ideas which in time become widely valued - informally valued and immanent from action - inevitably integrate the core values of a society, i.e. those that sustain the functioning and reproduction of existing social structures (Dubois \& Beauvois, 2005). Because these new ideas might eventually integrate fundamental societal values, instrumental for the acquisition of social and material outcomes, they can be intentionally used in the goal of obtaining rewards as a member of a society (Schenkler, 1996, p. 316). By approaching interpersonal situations as impregnated with the values and norms associated with social representations active and shared at a societal level, the sociocognitive approach proposes tools sensitive to what are the interpersonal consequences of adopting (or not) these ideas. Therefore, based on it we propose that once these new and transcendent ideas are appropriated, they also become implicitly expected and used in interpersonal contexts, especially evaluative ones.

Also relevant for understanding the appropriation process is to take into account 
an assumption from TRS: that meaning travels between different 'universes', and in the appropriation of legal innovation it travels from the reified to the consensual (Moscovici, 2000; Castro \& Mouro, 2011). The reified universe of formal and institutional rules sees the world as a system void of identity - where "truth is confirmed by its conformity to prescribed procedures" (Moscovici, 1988, p. 233). In the consensual universe - where knowledge is invested with shared meaning and contextualized (Boulanger \& Christensen, in press) - "the waning art of conversation" is what thinking thrives upon (Moscovici, 2000, p. 34). So for diagnosing the extent to which meaning is travelling and change happening, the 'diagnostic' criteria need to incorporate one of the central features of the art of conversation and communication: its orientation to the Other, its adjustment to what are deemed the characteristics of the audience (Goffman, 1959). It is important to specify, however, that cultural change rarely is linear (Jensen \& Wagoner, 2009). The accommodation of reified ideas into consensual worlds can either take place progressively (Doise, 2001), be resisted blatantly (), or tolerated in general but subtly resisted contextually (Castro, 2012; Castro \& Batel, 2008).

\section{The consensualisation dimension: awareness and meta-representation}

The appropriation process described above explains the individual level outcomes of broader cultural, societal change processes triggered by formal laws. Meanwhile, the appropriation of these new meanings and behaviours is contextualized by social groups, where individuals are able to witness either first-hand or through meta-knowledge (Elcheroth et al., 2011) how consensual and socially normative are these (once new) ideas.

Meta-knowledge about how consensual a new idea or behaviour is becoming in the "battle of ideas" of a society (Moscovici \& Marková, 2000) plays an important role 
in either accelerating or slowing down change (Bertoldo, 2014; Elcheroth et al., 2011; Mouro \& Castro, 2016). Meta-knowledge about what the Other is valuing, doing or saying guides meta-expectations of the Other about the Self, and vice-versa (Elcheroth et al., 2011; Mouro \& Castro, 2016). This can be seen, for instance, in the different meanings and informal norms associated with wearing the veil in Muslim majority or minority societies (Wagner, Sen, Permanadeli, \& Howarth, 2012). Meta-knowledge (Elcheroth et al., 2011) about how consensual a given idea is across various social groups of a society can moreover be associated with different types of representations: hegemonic, polemic or emancipated representations (Moscovici, 1988).

Hegemonic social representations are uniform and coercive in a society (Moscovici, 1988). This type of social representations are widely shared, having become immanent in social practices and integrated in institutional arrangements. For example, one of the aims of the United Nations is to make human rights a hegemonic idea: both nationwide and, in this case, worldwide (Doise, 2001). The sociocognitive approach considers these hegemonic ideas as 'normative', i.e. instrumental for the functioning and reproduction of social structures and institutions. Examples of normative ideas in our time studied by this approach are individualism, which considerably impacts "the attribution processes of individuals" (Dubois \& Beauvois, 2005, p. 123); or the belief in a just world (Alves \& Correia, 2008).

Polemic representations, often involving group conflicts, offer incompatible versions of an object circulating in society (Moscovici, 1988). They incorporate identity elements (Kus, Liu, \& Ward, 2013; Vala, Garcia- Marques, Gouveia-Pereira, \& Lopes, 1998) carrying holomorphic information (Wagner, 1995), i.e. meta-knowledge about how 'our' representations differ from 'theirs' (Raudsepp, 2005). From a sociocognitive perspective, these representations might be normative in the context of one social group, 
and counter-normative - and de-valued - in another competing group or context. In other words, different conflicting versions are shared by different 'audiences' (Goffmann, 1959) that value and expect different (and sometimes conflicting) practices. An example of this type of representations - and of the social norms they associate with - are the polarized views about the Soviet past held by Estonian and by Russian communities in Estonia (Kus et al., 2013).

Finally, emancipated representations are those that have outgrown their group of origin to spread across "subgroups that are in more or less close contact. Each subgroup creates its own version and shares it with the others" (Moscovici, 1988, p. 221). They include ideas and values already familiar and shared-e.g. human rights or environmental conservation. Their abstract formulations often harness wide social value across a society (Staerklé \& Clémence, 2004), but the specific behavioural consequences that are to be drawn from them are not stable, or equal in different groups and contexts (Mouro \& Castro, 2012; Staerklé \& Clémence, 2004). This type of representational dynamics allows the individual to contextually justify the infringement of a requirement by resorting to a different context where the expression of a different opinion or behaviour is acceptable (Uzelgun, Mohammed, Lewinski, \& Castro, 2015), i.e. by making distinctions between contexts of action (Mouro \& Castro, 2012). For example: there are various versions of what being an ecologist means and not all of them require engaging in action to the same extent (Castro, 2012). In sum, emancipated representations reached the "level of overt agreement, but their creative potential for initiating new practices remains poor"” (Castro \& Batel, 2008, p. 482). Various studies focusing on cultural change promoted through legal innovation demonstrate an

\footnotetext{
${ }^{1}$ This phrase refers to the fact that emancipated representations help to convey new meaning (present in emancipated representations) to old practices. In short, this disconnection hampers the creative potential for initiating new practices in accordance with the ideas existing in the representation, since they easily "make sense".
} 
emancipated dynamic: they show how abstract ideas (e.g. human rights, organ donation, biodiversity conservation) are valued and supported, but less expressed through concrete behaviours (Moloney, Hall, \& Walker, 2005; Mouro \& Castro, 2012; Staerklé \& Clémence, 2004). In sociocognitive terms, these representations show a gap between what is expected regarding beliefs and behaviours, with a social value that is adaptable to the different presentation contexts (Gilibert \& Cambon, 2003).

\section{*** Insert TABLE 1 here ***}

The main theoretical arguments of the two above-described dimensions of appropriation and consensualisation are synthesised on Table 1. These two dimensions contribute to expanding our understanding of cultural change at different levels of analysis (Doise, 1982). The first dimension, appropriation, is concerned with how the individual progressively incorporates societal requirements in his/her behaviour, irrespective of his/her group affiliation. The second, the consensualisation dimension, takes into account meta-knowledge about how these new ideas gradually spread across social groups and have become either hegemonic, polemic or emancipated (Moscovici, 1988).

\section{Summary and presentation of the studies}

This article proposes that a better understanding of cultural change promoted by legal innovations can be achieved by combining the social representations (Moscovici, 2000) and the sociocognitive approaches (Dubois, 2003). More specifically, it views their integration as useful to analyse at which level have new ideas and behaviours supported by new laws become (1) appropriated, and thus implicit in individual 
behaviour; and (2) consensual across social groups. In this sense, based on them we propose diagnostic criteria that can be useful for assessing the progress of the social change generated by new laws. These diagnostic criteria involve the assessment of two main aspects: (1) the extent to which the new laws, as well as the representations they incorporate, have moved from a reified to a consensual universe, integrating the new social practices proposed (communicative or material) as immanent to behaviours (appropriation dimension); (2) the extent of the perceived consensus about how society has integrated these changes. This integration can happen in a hegemonic way, in a polemic way and in an emancipated way (consensualisation dimension).

With a specific focus on communicative practices, this diagnostic proposal specifically looks at how the ideas and behaviours proposed by the new laws are 'used' in Self-Other relations. The analyses of the implicit interpersonal expectations can be carried out through a variety of methods, but the experimental paradigms of the sociocognitive approach (Dubois, 2003) present a number of advantages for our goals. Seeking to bring implicit phenomena to psychosocial scrutiny (Dubois, 2003), by tapping into how social knowledge is implicitly valued and asking participants to enter a role-play situation (e.g. imagining themselves communicating in Self-Other relations), these experimental paradigms take direct advantage of a fact that many others overlook: that participants of experimental studies "walk into the lab environment as carriers of systems of meaning, as citizens of socio-cultural worlds that they cannot just shrug off" (Jovchelovitch, 2011, p. 12.4). Proposing the experimental situation as a social situation (Farr, 1984), these paradigms explicitly ask participants to make use of their cultural competences. This allows to explore if the norms incorporated in once reified, institutional, proposals have permeated everyday life, also influencing communicative practices in informal contexts. Once these social interaction expectations, implicit in 
interpersonal judgement, are coupled with a dynamic approach to social change (see Table 1), they contribute to expanding our capacity for diagnosing the pace of social change.

As an illustration of how the experimental paradigms of the sociocognitive approach can be used to diagnose cultural change and the social value new meaning acquires when moving from reified to consensual universes we use in this article two paradigms: the self-presentation and the hetero-judgement paradigms (Gilibert \& Cambon, 2003). With the first we assume that if the representations incorporated in the new laws are used for conveying a positive Self-image, then they are socially valued (Jellison \& Green, 1982; Alves \& Correia, 2008); with the second we assume that if Others expressing such representations are positively judged, they are socially valued. The specific assumptions orienting the experimental design of each study are presented in the next sections.

Meanwhile it is important to underline the importance, and at the same time the difficulty, of integrating these two theories. The long and rigid separation in social psychology between experimental and other methods has hampered the crossfertilization between different social psychological approaches (Jovchelovitch, 2011) maintaining research traditions fragmented (Moscovici, 1989) and segregated. In this context, these paradigms - enabling the use of standardized role-playing of communicative practices as a resource for diagnosing cultural change - can offer a more integrative view of processes of cultural transformation, by providing rich descriptions of them (Moscovici, 1989, p. 414), rather than seeking premature explanations for them.

Below we will first present the results of how participants made communicative use of conservation beliefs and behaviours. Then, in a second moment, we will interpret what these results mean by drawing on the theoretical frame above presented. 


\section{Study 1 - Self-presentation in context: Anticipating the social gaze}

Participants were placed in a role-playing situation by being asked to present themselves as part of a job interview to a possible future employer from either an Ecological Institute or a Cement Plant. The Ecological Institute was described to participants as "very active in exerting public pressure for the respect of environmental laws and regulations". The Cement Plant was described as "publicly known to suffer pressure from environmental groups because of the environmental impact of its extractive activities". Respondents were asked to convey either a positive self-image (imagining they very much wanted the job) or a negative one (they did not want the job, but could not refuse it directly in order not be excluded from the data-base) by answering a questionnaire. The questionnaire comprised questions about conservation beliefs and behaviours regarding recycling, and energy and water saving.

Recently, the positive social value of expressing conservation beliefs and behaviours has been demonstrated through self-presentation in EU member-states with environmental laws based on EU Directives (Félonneau \& Becker, 2008). However, the expression of how Self-presentations adjust to different Others, part of different social contexts or audiences, has not yet been explored.

In relation to the appropriation dimension, this study will be able to identify if resource-conservation policies applied today in Portugal - and based on EU Directives - have become immanent, part of what is implicitly expected in interpersonal encounters, and therefore infiltrated the Portuguese 'consensual universe'. This will be observed if participants rely on pro-conservation ideas to present a good image, and anti-conservation ones to pass a negative self-image, and there is a significant difference between both images, when presenting themselves in different contexts.. 
From a consensualisation perspective, this study will allow to observe whether participants adapt their presentation strategies to contexts where resource-conservation ideas are differently valued - an Ecological Institute or a Cement Plant. A stable expression of conservation beliefs and behaviours across contexts would suggest a wide social consensus, close to hegemonic representations. A stable expression of conservation beliefs, accompanied by a contextually adapted expression of behaviours would be indicative of emancipated representations, since these ideas tend to be overall well-accepted, adaptable and their inconsistency with behaviours is tolerated (Bertoldo, 2014). And finally a dynamic where both beliefs and behaviours are differently used across contexts would reveal a dynamic typical of polemic representations.

\section{Method}

\section{Procedure and participants}

Participants were approached in a classroom and randomly assigned to one of four conditions: self-presentation to convey a positive or negative self-image to a potential employer (either the Cement Plant employer or the Ecological Institute employer). A total of 155 Portuguese university students participated in the study. Their mean age was 22.5 years $(19-53, D P=4.5)$ and $58 \%$ were female.

\section{Variables}

Conservation beliefs: five items were used ( $\alpha=.75$; “It doesn't make sense to worry about my personal water consumption when industries are the biggest water consumers" (reversed); "I see the saving of energy as something positive"; "The fact that I save energy has no impact on environmental protection" (reversed); "I see the recycling of selective deposit containers as positive" and "I see the recycling of paper as positive"; scale: 1 = totally disagree to $7=$ totally agree).

Conservation behaviours: five items were used ( $\alpha=.62$; "I do my best not to 
waste water in my home"; "I do not leave electronic devices on standby"; "At home, I use energy without worrying about saving it" (reversed); "I deposit my used batteries in the recycling container" and "I sort and take out my packages for recycling"; scale: $1=$ never to $7=$ always).

\section{Results}

Results of a three-way ANOVA ${ }^{2}$ with environmental belief or behaviour as repeated factor showed that, overall, both conservation beliefs $\left(M_{\mathrm{pos}}=6.32 ; M_{\mathrm{neg}}=\right.$ $5.13 ; t(152)=5.6, p<.001)$ and behaviours $\left(M_{\mathrm{pos}}=5.21 ; M_{\mathrm{neg}}=4.49 ; t(122)=2.9, p<\right.$ .01) have higher means when expressed in a positive than in a negative presentation $(F(1,119)=24.4, p<.001)$. This suggests that these beliefs and behaviours have a positive social value.

\section{***Insert FIGURE 1 here ***}

Moreover the presentation strategies change according to the context $(F(1,119)=$ 10.6, $p<.01$ ). When presentations are made to an Ecological Institute employer (Figure 1), differences between positive and negative presentations are significantly different (Beliefs: $M_{\text {pos }}=6.54 ; M_{\text {neg }}=4.65 ; t(75)=6.9, p<.001 ;$ Behaviours: $M_{\text {pos }}=5.31 ; M_{\text {neg }}=$ $4.3 ; t(59)=3.3, p<.01)$. This is not the case when presentations are made to a Cement Plant employer (Beliefs: $M_{\mathrm{pos}}=6.1 ; M_{\mathrm{neg}}=5.76 ; t(75)=.9, p=n s ;$ Behaviours: $M_{\mathrm{pos}}=$ $\left.4.94 ; M_{\text {neg }}=4.68 ; t(61)=.8, p=n s\right)$. Figure 1 presents these results.

\section{Discussion}

The results of this study suggest a valorisation of resource-conservation beliefs and behaviours in the Portuguese society. From an appropriation perspective, they

\footnotetext{
${ }^{2}$ ANOVA 2 (presentation type: positive/negative) by 2 (presentation context: ecological institute/cement plant) by 2 (outcome variable: belief/behaviour) with repeated measures on the last factor.
} 
illustrate how conservation ideas and behaviours, initially proposed by a reified universe as part of formal norms and regulations (Castro, 2012) are used for positive self-presentations-i.e. conservation beliefs and behaviours have become informally valued in Portugal.

However, an analysis from a consensualisation perspective adds nuances to this general conclusion. In the context aligned with environmental laws (Ecological Institute), participants used conservation beliefs and behaviours to make positive and negative presentations that are significantly different. In the Cement Plant context this was not the case: conservation beliefs and behaviours are equivalent for positive and negative presentations. This can suggest that respondents are not totally sure of what to value and devalue in that context, and so their choices do not yield a clear difference between negative and positive presentations. Participants seem to be responding to a generic rule indicating that, in general, conservation ideas and behaviours are socially valued (hence the high means for both beliefs in and behaviours); however, they seem to be unsure of their social value in this specific context (hence the lack of difference between positive and negative presentations). This pattern of differences extends previous findings by showing that the valorisation of resource-conservation is (still) context-dependent.

Despite the usefulness of the self-presentation paradigm for demonstrating the valorisation of some core-representations "nothing proves that the impression they (participants) give is in fact an impression which they themselves would valorise if they were given by another" (Gilibert \& Cambon, 2003, p. 45). These concerns will be addressed in the next study through the hetero-judgement paradigm.

Study 2 - Hetero-judgements and the social gaze we share 
In this second study, cultural change towards resource-conservation will be assessed by placing participants in the role of the social 'other', asking them to judge someone else. Previous studies have shown that social judgments are organised around two main dimensions: one aggregating traits related with friendliness and sympathy (warmth), and another aggregating intellectual and task-related traits (competence) (Fiske, Cuddy \& Glick, 2002).

From an appropriation perspective, previous studies have shown that in the 1990s recycling was associated with a caring image - a warmth trait -, and negatively associated with ambition - a competence trait (Sadalla \& Krull, 1995). This study was replicated in the following decade and competence traits (like 'competitive' and 'ambitious') were no longer affected by whether or not the person performed conservation behaviours (see Welte \& Anastasio, 2010). These results suggest that representations associated with conservation practices have meanwhile acquired positive social value. This study will use the same hetero-judgement approach to analyse how are these beliefs and behaviours perceived when displayed by someone else in Portugal. If someone presenting high conservation beliefs and behaviours is better judged - or seen as warmer and more competent - than someone presenting low conservation beliefs and behaviours, it would demonstrate the valorisation of these beliefs and behaviours and therefore validate the results of Study 1 through another paradigm.

From a consensualisation perspective, this study will further clarify the extent to which inconsistency between conservation beliefs and behaviour is tolerated in the Portuguese context. More specifically, the perceived warmth and competence of two consistent targets (one pro-conservation and one anti-conservation) will be compared with those of an inconsistent target (high conservation beliefs and low behaviours). 


\section{Method}

\section{Procedure and participants}

Participants were invited to take part in an impression formation task. They were given a pre-filled questionnaire (the same as the one used in the previous study), and asked to imagine what the person who had supposedly filled it in was like. The prefilled questionnaire expressed one of the three following profiles:

Pro-conservation (strong conservation beliefs and frequent conservation behaviours) where very positive answers ( 7 in a 7 -point scale) were given to about $1 / 3$ of the questions and positive answers (6) to the rest of the items.

Anti-conservation (weak beliefs and infrequent behaviours) where very negative answers (1) were given to about $1 / 3$ of the items, and negative answers ( 2 or 3 ) to the rest of the items.

Inconsistent (strong beliefs but infrequent behaviours) where the displayed beliefs were equivalent to those displayed by the pro-conservation profile, and the displayed behaviours were equivalent to those displayed by the anti-conservation profile.

Participants were then requested to rate that person on a set of competence and warmth traits (Fiske et al., 2002). A manipulation-check task at the end of the questionnaire excluded those participants who could not correctly characterise the proposed profile in terms of conservation beliefs and behaviours.

Participants were 72 Portuguese university students: 29 participants in the proconservation condition, 17 in the inconsistent condition and 26 in the anti-conservation condition. They were on average 21.8 years old $(18-48, D P=6.99)$, and mostly female $(62 \%)$

\section{Variables}

The competence traits (talented, intelligent, capable and competent; $\alpha=.82$ ) and the warmth traits (sincere, good-natured, friendly, tolerant, warm; $\alpha=.73$ ) were 
averaged in two indexes. All traits were measured on a 7-point scale (from 1 - not characteristic at all to 7 - totally characteristic).

\section{Results}

The results of a two-way ANOVA ${ }^{3}$ with repeated measures on the judgement dimension showed a main effect of the judgment profile (pro-conservation, anticonservation, inconsistent $)(F(2,69)=22.4, p<.001)$ and an interaction between the profile and the judgement dimension (competence and warmth) $(F(2,69)=6.84, p<$ $.01)$.

Additional partial comparisons with three one-way ANOVAs, one for each judgement dimension, were performed ${ }^{4}$. Post hoc tests with Bonferroni pairwise comparisons show that the pro-conservation profile is better judged than the anticonservation one on both dimensions (all $p$ 's $<.001$ ).

\section{*** Insert TABLE 2 here ***}

In comparison with the inconsistent profile, the pro-conservation profile is better judged in terms of competence $(p<.001)$, but equivalent in terms of warmth $(p=.158)$. Still in relation to the inconsistent profile, as expected the anti-conservation one is better judged in terms of perceived warmth $(p<.05)$, but is seen as equally competent $(p=$ $.33)$.

\section{Discussion}

Results of this study provide an additional illustration of the different levels at play in the processes of cultural change taking place in Portugal following the

\footnotetext{
${ }^{3}$ ANOVA 3 (profile: pro-conservation/inconsistent/anti-conservation) X 3 (judgement dimension: competence/warmth).

${ }^{4}$ competence: $F(2,69)=24.91, p<.001$; warmth: $F(2,69)=24.91, p<.001$
} 
implementation of resource-conservation laws. More specifically, from an appropriation perspective, these results demonstrate how a pro-conservation person is better judged than an anti-conservation person in both warmth and competence dimensions. In other words, when assuming the role of a social 'Other', participants attribute more social value to the pro-conservation profile in relation to the anticonservation and the inconsistent ones.

Results further show that the inconsistent profile is judged as equally warm as the consistent pro-conservation profile - and warmer than the anti-conservation. Despite not presenting conservation behaviours, the profile displaying the classic beliefbehaviour gap does not fail to express the socially valued conservation beliefs, and is shielded from the harsher evaluation addressed to the anti-conservation profile. The shield is however not perfect, as the inconsistent profile is seen as less competent than the pro-conservation one. From a consensualisation perspective, thus, by showing some tolerance for the inconsistent profile, these results thus indicate a general and abstract valorisation of conservation ideas - a pattern that is characteristic of emancipated representations (Castro \& Mouro, 2011).

\section{General Discussion}

The fact that numerous laws and regulations promoting resource-conservation entered into force in EU countries in recent decades has created an important opportunity for studying processes of cultural change fostered by the policy and legal spheres (Castro, 2012). In this context, the enduring inconsistency between the expressed support for resource-conservation ideas and the corresponding behaviours has specifically brought to the fore the need to develop a better understanding of the psychosocial processes through which formal laws, crafted in legal/reified universes (Moscovici, 2000) over time also become (or fail to become) informal norms, 
maintained and reproduced in consensual universes (Moscovici, 2000; Castro, 2012; Castro \& Batel, 2008). This article thus combined elements from the social representations theory (Moscovici, 2000) and the sociocognitive approach to norms (Dubois, 2003) for organising an integrated theoretical framework capable of diagnosing the extent to which cultural change fostered by the legal/reified universe has been successful to the point of influencing the everyday informal valorisation of the ideas it proposes. More specifically, this integrated framework proposes that the cultural change triggered by laws can, through social debate and interaction, be progressively incorporated by society to the level of influencing and being expected in interpersonal communicative practices. When these social expectations, implicit in interpersonal judgement, are framed by a dynamic approach to social change (see Table 1), they can contribute to our capacity for diagnosing the pace of social change.

The integrated framework we proposed assumes that social innovation generated at a societal level by laws can be tapped by the appropriation dimension at the level of the individual; and by the consensualisation dimension at the positional and intergroup levels (Doise, 1982).

(1) Appropriation dimension: helps analysing whether people use ideas and behaviours promoted in legal innovations when seeking to present a good or bad self-image; and use these ideas and behaviours as criteria to judge the Other;

(2) Consensualisation dimension: helps analysing how people use these ideas and behaviours when they (a) present themselves to different 'audiences' - and thus helps diagnosing the status of the representations the new laws incorporate - polemical if beliefs and behaviours are altered and adapted to different audiences; emancipated if mainly behaviours are 
adapted; and hegemonic if beliefs and behaviours are used in the same way irrespective of the context; and (b) judge targets expressing different levels of beliefs and behaviours - tolerant judgement of targets presenting inconsistent beliefs and behaviours would suggest emancipated representations, while harsher judgements would suggest hegemonic representations (Bertoldo, 2014).

With the goal of diagnosing the extent to which conservation ideas, initially proposed by legal regulations, impact interpersonal expectations in different imagined contexts of the Portuguese society, two studies were conducted using the paradigms of the sociocognitive approach to social norms: the self-presentation (Study 1) and the hetero-judgement (Study 2) paradigms.

In relation to the appropriation dimension, both studies illustrate how these beliefs and behaviours are today informal valued. Study 1 shows how Portuguese university students - as a EU member-state with resource-conservation laws - recognise the informal value of conservation ideas and behaviours, since when asked to present themselves in a positive manner, they offer high agreement with them. Furthermore, participants make use of conservation ideas and behaviours in a way that corroborates previous studies conducted in other EU member-states (Félonneau \& Becker, 2008).

Moreover, when participants change perspective and take the place of evaluators, they make use of the informal value of conservation beliefs and behaviours to judge other people. In this situation, a person with a pro-conservation profile (strong conservation beliefs and frequent behaviours) is better judged than a person with an anti-conservation profile (weak conservation beliefs and infrequent behaviours), in both the warmth and the competence dimensions. Together with Study 1, these results thus suggest that even when they take on the role of a social 'other', participants attribute 
more social value to the pro-conservation profile than to the anti-conservation and the inconsistent ones.

In what concerns the consensualisation dimension, results of the first study demonstrate that the observed valorisation of conservation beliefs and behaviours is context-dependent: university students are aware of how different social groups think about the environment and adapt their self-presentation strategies accordingly so as to be well-seen. This implicit acknowledgement and adaptation to different audiences constitutes a demonstration that conservation goals have not achieved a social value typical of hegemonic representations, nor do they, nevertheless, sharply divide groups, as do polemic representations.

Results of the second study also illustrate how the expression of conservation beliefs (a more abstract level) is socially valued, and crucial for people to be positively seen as competent and warm. The expression of conservation behaviours (concrete) is less of a requirement. Results show that a profile presenting infrequent conservation behaviours, but expressing strong conservation beliefs is judged to be as warm as one presenting both high conservation beliefs and behaviours. These findings illustrate the strength and 'abstractness' of the value attached to environmental ideas, which can then more easily be transferred between contexts, often without necessarily calling into question their pragmatic adaptability through concrete behaviours. The informal social value attached to these ideas, and this tolerance for inconsistent behaviour, thus seem typical characteristics of emancipated representations, those more amenable to context, and negotiable (Moscovici, 1988; Mouro \& Castro, 2012).

This integration of social representations theory (Moscovici, 2000) and the sociocognitive approach to norms (Dubois, 2003) provides an insightful and innovative 
look into the processes that implicitly, yet actively, accompany social and cultural changes promoted by new laws and policies (Castro, 2012).

The fact that our samples were exclusively composed of university students can be considered a limitation in terms of how are they representative of the Portuguese society as a whole. Nevertheless, university education in Portugal is overall less expensive than in many other EU countries, allowing students of a variety of social backgrounds to attend university (EC, 2016). Moreover, the fact that university students are going through formal education exposes them - often as part of the curricula - to social representations and formal norms aligned with public policies . Still, a comparison with other groups of the Portuguese society could better identify at which stage are we in the generalisation of the environmental cultural change (Castro \& Mouro, 2011).

We believe this joint approach has the potential to stimulate future cross-cultural studies, as well as to open up new avenues for exploring other issues (e.g. gay marriage, cannabis legalisation), in different fields of importance to cultural psychology.

\section{References}

Alves, H., \& Correia, I. (2008). On the normativity of expressing the belief in a just world: Empirical evidence. Social Justice Research, 21, 106-118.

Batel, S., Devine-Wright, P., \& Tangeland, T. (2013). Social acceptance of low carbon energy and associated infrastructures: A critical discussion. Energy Policy, 58, 1-5.

Bertoldo, R. (2014). A Valorização social do pró-ambientalismo enquadrado por normas formais: Uma análise psicossocial comparativa entre Brasil e Portugal (Unpublished doctoral dissertation). Lisbon University Institute, ISCTE-IUL, Lisbon. Available at https://repositorio.iscte-iul.pt/handle/10071/8490

Börzel, T. \& Fagan, A. (2015). Environmental governance in South East Europe/Western Balkans: Reassessing the transformative power of Europe. Environment and Planning C: Government and Policy, 47, 1-16. 
Boulanger, D. (2017). Representing the vagueness within dialogical self: Presence and absence of the object in between self and community. The International Journal for Dialogical Sciences, 10(2), 117-130.

Boulanger, D. \& Christensen, B. (in press). Social representations as social forms and aesthetic phenomena: Dialogue between Moscovici and Simmel. In L. Tateo (Ed.), An old melody in a new song: Aesthetics and psychology. Springer.

Castro, P. (2012). Legal innovation for social change: exploring change and resistance to different types of sustainability laws. Political Psychology, 33, 105-121.

Castro, P., \& Batel, S. (2008). Social representation, change and resistance: On the difficulties of generalizing new norms. Culture \& Psychology, 14, 475-497.

Castro, P., \& Mouro, C. (2011). Psycho-social processes in dealing with legal innovation in the community: Insights from biodiversity conservation. American Journal of Community Psychology, 47(3-4), 362-73.

Doise, W. (1980). Levels of explanation in the European Journal of Social Psychology. European Journal of Social Psychology, 10, 213-31.

Doise, W. (2001). Human rights studied as normative social representations. In K. Deaux \& G. Philogène (Eds.), Representations of the social (pp. 96-112). Oxford: Blackwell.

Dubois, N. (2003). The concept of norm. In N. Dubois (Ed.), A sociocognitive approach to social norms (pp. 1-15). London: Routledge.

Dubois, N., \& Beauvois, J.-L. (2005). Normativeness and individualism. European Journal of Social Psychology, 35, 123-146.

EC [European Commission] (2016). National student fee and support systems in European higher education - 2016/17. Eurydice Facts and Figures. Luxembourg: Publications Office of the European Union.

Elcheroth, G., Doise, W., \& Reicher, S. (2011). On the knowledge of politics and the politics of knowledge: How a social representations approach helps us rethink the subject of political psychology. Political Psychology, 32, 729-758.

Farr, R. (1985). Social Representations: their role in the design and execution of laboratory experiments, in R. M. Farr and S. Moscovici (Eds.), Social Representations (pp. 125-147). Cambridge: CUP.

Félonneau, M., \& Becker, M. (2008). Pro-environmental attitudes and behaviour: revealing perceived social desirability. Revue Internationale de Psychologie Sociale, 21, 25-53.

Fiske, S. T., Cuddy, A. J. C., \& Glick, P. (2002). A model of (often mixed) stereotype content: Competence and warmth respectively follow from perceived status and competition. Journal of Personality and Social Psychology, 82, 878 -902. 
Foucault, M. (1982). The subject and power. In H. Dreyfus \& P. Rabinow (Eds.), Michel Foucault: Beyond structuralism and hermeneutics (pp. 208-226). Brighton: Harvester.

Gaskell, G., Allansdottir, A., Allum, N., Castro, P., Esmer, Y., Fischler, C., ... Wager, W. (2011). The 2010 Eurobarometer on the life sciences. Nature Biotechnology, 29(2), 113-4.

Giddens, A. (2009) The politics of Climate Change. Polity Press: Cambridge.

Gillibert, D., \& Cambon, L. (2003). Paradigms of the sociocognitive approach. In N. Dubois, A sociocognitive approach to social norms (pp. 38-69). London: Routledge.

Goffman, E. (1959). The presentation of self in everyday life. Garden City, NY: DoubleDay.

Grossen, M., \& Orvig, A. S. (2011). Dialogism and dialogicality in the study of the self. Culture \& Psychology, 17, 491-509.

Harré, R. (1998). The epistemology of social representations. In U. Flick (Ed.), The Psychology of the social (pp. 129-37). Cambridge: Cambridge University Press.

Harré, R. (2002). Rom Harré on social structure and social change: Social reality and the myth of social structure. European Journal of Social Theory, 5, 111-23.

Jellison, J. M., \& Green, J. (1982). A self-presentation approach to the fundamental attribution error: The norm of internality. Journal of Personality and Social Psychology, 40, 643-649.

Jensen, E., \& Wagoner, B. (2009). Continuing commentary: A Cyclical model of Social Change. Culture \& Psychology, 15(2), 217-228.

Jovchelovitch, S. (2011). Putting experiments in their place: Commentary on Robert Farr's "Social Representations: Their role in the design and execution of laboratory experiments" In R. M. Farr and S. Moscovici (Eds.), (1984), Social Representations (pp. 125-147). Cambridge: CUP. Papers on Social Representations, 20, 12.1-12.12.

Kus, L., Liu, J., \& Ward, C. (2013). Relative deprivation versus system justification: Polemical social representations and identity positioning in a post-Soviet society. European Journal of Social Psychology, 43, 423-437.

Lavergne, K. J., \& Pelletier, L. G. (2015). Predicting individual differences in the choice of strategy to compensate for attitude-behaviour inconsistencies in the environmental domain. Journal of Environmental Psychology, 44, 135-148.

Lidskog, R. (2014). Representing and regulating nature: Boundary organisations, portable representations, and the science-policy interface. Environmental Politics, 23(4), 670-687. 
Marková I., Linell, P., Grossen, M., \& Orvig A. S. (2007). Dialogue in focus groups: Exploring socially shared knowledge. London: Equinox.

Marková, I. (2006). Dialogicality and social representations: The dynamics of mind. Cambridge: Cambridge University Press.

Moloney, G., Hall, R., \& Walker, I. (2005). Social representations and themata: The construction and functioning of social knowledge about donation and transplantation. The British Journal of Social Psychology, 44, 415-41.

Moscovici, S. (1988). Notes towards a description of social representations. European Journal of Social Psychology, 18, 211-250.

Moscovici, S. (1989). Preconditions for explanation in social psychology. European Journal of Social Psychology, 19, 407-430.

Moscovici, S. (2000). Social representations: Explorations in social psychology. London: Polity Press.

Moscovici, S., \& Marková, I. (2000). Ideas and their development: A dialogue between Serge Moscovici and Ivana Marková. In S. Moscovici, Social representations: Explorations in social psychology (G. Duveen. Ed.). Oxford: Polity Press.

Mouro, C. \& Castro, P. (2012). Cognitive polyphasia in the reception of legal innovations for biodiversity conservation. Papers on Social Representations, 21, 3.1-3.21

Mouro, C., \& Castro, P. (2016). Self-other relations in biodiversity conservation in the community: Representational processes and adjustment to new actions. Journal of Community \& Applied Social Psychology, 26, 340-353.

Raudsepp, M. (2005). Why is it so difficult to understand the theory of social representations? Culture Psychology, 11, 455-468.

Rogoff, B. (1995). Observing sociocultural activity on three planes: Participatory appropriation, guided participation, and apprenticeship. In: J. V. Wertsch, P. D. Rio, \& A. Alvarez (Eds), Sociocultural studies of mind (pp. 139-164). Cambridge, UK: Cambridge University Press.

Sadalla, E., \& Krull, J. (1995). Self-presentational barriers to resource conservation. Environment \& Behavior, 27, 328-353.

Schenkler, B. R. (1996). Impression management. In: A. S. Manstead \& M. Hewstone (eds.), The Blackwell Encyclopedia for Social Psychology (pp. 314-319), Oxford: Blackwell.

Staerklé, C., \& Clémence, A. (2004). Why people are committed to human rights and still tolerate their violation: A contextual analysis of the principle-application gap. Social Justice Research, 17, 389-406. 
Uzelgun, M. A., Mohammed, D., Lewinski, M., \& Castro, P. (2015). Managing disagreement through yes, but... constructions: An argumentative analysis. Discourse Studies, 17(4), 467-484. http://doi.org/10.1177/1461445615578965

Vala, J., Garcia-Marques, L., Gouveia-Pereira, M., \& Lopes, D. (1998). Validation of polemical social representations: introducing the intergroup differentiation of heterogeneity. Social Science Information, 37, 469-92.

Valsiner, J. (2003). Beyond social representations: A theory of enablement. Papers on Social Representations, 12, 7.1-7.16.

Valsiner, J., \& Lawrence, J. A. (1997). Human development in culture across the life span. In J. W. Berry, P. R. Dasen, \& T. S. Saraswathi (Eds.), Handbook of CrossCultural Psychology. Needham Heights: Allyn \& Bacon.

Wagner, W. (1995). Social representations, group affiliation, and projection: knowing the limits of validity. European Journal of Social Psychology, 25, 125-139.

Wagner, W., Sen, R., Permanadeli, R., \& Howarth, C. S. (2012). The veil and Muslim women's identity: cultural pressures and resistance to stereotyping. Culture \& Psychology, 18(4), 521-541.

Welte, T. H. L., \& Anastasio, P. A. (2010). To conserve or not to conserve: Is status the question? Environment and Behavior, 42(6), 845-863.

Zittoun, T., \& Gillespie, A. (2015). Internalization: How culture becomes mind. Culture \& Psychology, 21(4), 477-491. http://doi.org/10.1177/1354067X15615809 
Table 1. Schematic synthesis of the main concepts proposed to understand the dynamics of social change and its possible outcomes.

\begin{tabular}{|c|c|c|c|c|c|}
\hline \multirow{3}{*}{ } & \multicolumn{2}{|c|}{ Appropriation } & \multicolumn{3}{|c|}{ Consensualisation } \\
\hline & Transcendent & Immanent & Emancipated & Polemic & Hegemonic \\
\hline & $\begin{array}{l}\text { New ideas } \\
\text { remain as } \\
\text { external } \\
\text { instructions, } \\
\text { decontextualized, } \\
\text { with little impact } \\
\text { on behaviour. }\end{array}$ & $\begin{array}{l}\text { Observance of } \\
\text { (what once } \\
\text { were) new } \\
\text { ideas is now } \\
\text { implicit in } \\
\text { behaviour. }\end{array}$ & $\begin{array}{l}\text { Widely } \\
\text { socially shared, } \\
\text { support for } \\
\text { these ideas and } \\
\text { behaviours is } \\
\text { susceptible to } \\
\text { contextual } \\
\text { influence. }\end{array}$ & $\begin{array}{l}\text { The expression of } \\
\text { these ideas and } \\
\text { behaviours } \\
\text { identifies the } \\
\text { individual as } \\
\text { member of a } \\
\text { certain group, } \\
\text { against other } \\
\text { group(s). }\end{array}$ & $\begin{array}{l}\text { The expression } \\
\text { of these ideas } \\
\text { and behaviours } \\
\text { is widespread } \\
\text { and implicit } \\
\text { across a nation, } \\
\text { culture or } \\
\text { society. }\end{array}$ \\
\hline 这 & $\begin{array}{l}\text { Normative } \\
\text { beliefs and } \\
\text { behaviours can } \\
\text { be used for } \\
\text { positive self- } \\
\text { presentation and } \\
\text { hetero- } \\
\text { judgement, } \\
\text { depending on the } \\
\text { context. }\end{array}$ & $\begin{array}{l}\text { Normative } \\
\text { beliefs and } \\
\text { behaviours are } \\
\text { used for } \\
\text { positive self- } \\
\text { presentation } \\
\text { and hetero- } \\
\text { judgement, in } \\
\text { most contexts. }\end{array}$ & $\begin{array}{l}\text { Normative } \\
\text { beliefs and } \\
\text { behaviours can } \\
\text { be used for } \\
\text { positive self- } \\
\text { presentation } \\
\text { and hetero- } \\
\text { judgement, } \\
\text { depending on } \\
\text { context. }\end{array}$ & $\begin{array}{l}\text { Normative beliefs } \\
\text { and behaviours are } \\
\text { used for positive } \\
\text { self-presentation } \\
\text { and hetero- } \\
\text { judgement in one } \\
\text { group, and are not } \\
\text { used in the } \\
\text { other(s). }\end{array}$ & $\begin{array}{l}\text { Normative } \\
\text { beliefs and } \\
\text { behaviours are } \\
\text { used for } \\
\text { positive self- } \\
\text { presentation } \\
\text { and hetero- } \\
\text { judgement, in } \\
\text { most contexts. }\end{array}$ \\
\hline
\end{tabular}


Table 2. Means of competence and warmth appraisal for the pro-conservation, inconsistent and anti-conservation targets.

\begin{tabular}{|c|c|c|c|c|c|c|c|c|c|}
\hline & \multicolumn{2}{|c|}{ Pro-conservation } & \multicolumn{2}{|c|}{ Inconsistent } & \multicolumn{2}{|c|}{$\begin{array}{c}\text { Anti- } \\
\text { conservation }\end{array}$} & \multirow[b]{2}{*}{$F(2,69)$} & \multirow[b]{2}{*}{$p$} & \multirow[b]{2}{*}{$\eta_{\mathrm{p} 2}$} \\
\hline & $M$ & $S D$ & $M$ & $S D$ & $M$ & $S D$ & & & \\
\hline Competence & 4.94 & 1.05 & 3.58 & 1.01 & 3.08 & .94 & 24.91 & $<.001$ & .42 \\
\hline Warmth & 4.70 & 1.01 & 4.18 & .70 & 3.50 & .73 & 13.4 & $<.001$ & .28 \\
\hline
\end{tabular}


— Pos pres. $\quad$ Neg. pres.

Figure 1. Differences between positive and negative presentations of conservation beliefs and behaviours, to an Ecological Institute and to a Cement Plant employer. 